\title{
Synergistic effects of multiwalled carbon nanotubes and core-shell particles on the toughness and physico-mechanical properties of epoxy resin: a systematic study
}

Ali Gharieh ( $\square$ gharieh.ali@gmail.com )

University of Isfahan

Mir Saeed Seyed Dorraji

University of Zanjan

\section{Research Article}

Keywords: Epoxy, nanocomposite, Carbon nanotubes, Core-shell particles, Optimization

Posted Date: May 26th, 2021

DOl: https://doi.org/10.21203/rs.3.rs-559033/v1

License: (a) (1) This work is licensed under a Creative Commons Attribution 4.0 International License.

Read Full License 


\section{Abstract}

Here, core-shell impact modifier particles (CSIMPs) and multiwalled carbon nanotubes (MWCNs) were used as reinforcing agents for improving toughness and tensile properties of epoxy resin. For this purpose, emulsion polymerization technique was exploited to fabricate poly(butyl acrylate-allyl methacrylate) core- poly (methyl methacrylate-glycidyl methacrylate) shell impact modifier particles with average particle size of $407 \mathrm{~nm}$. It was revealed that using a combination of the prepared CSIMPs and MWCNTs could significantly enhance toughness and tensile properties of epoxy resin. Also, it was observed that the dominant factors in enhancing the fracture toughness of the ternary composites are crack deflection/arresting as well as enlarged plastic deformation around the growing crack tip induced by the combination of rigid and soft particles. The Response Surface Methodology (RSM) with central composite design (CCD) was utilized to study the effects of the amounts of core-shell particles and multiwalled carbon nanotubes on the toughness and tensile properties of epoxy resin. The proposed quadratic models were in accordance with the experimental results with correlation coefficient more than $98 \%$. The optimum condition for maximum toughness, elastic modulus, and tensile strength were $3 \% \mathrm{wt}$. MWCNT and $1.03 \%$ wt. CSIMPs. The sample fabricated in optimal condition indicated toughness, elastic modulus, and tensile strength equal to $2.2 \mathrm{MPa} . \mathrm{m}^{1 / 2}, 3014.5 \mathrm{MPa}$ and $40.6 \mathrm{MPa}$, respectively.

\section{Introduction}

Epoxy resins, due to their great physico-mechanical attributes such as good chemical resistance, outstanding adhesion, and notable dimensional stability, are of paramount importance in various structural applications [1]. However, due to their high density of three-dimensional molecular structure, hardly can they resist toward growing of crack. This serious drawback limits their applications in many critical fields where a notable fracture strength or low-temperature toughness is required, such as aerospace and automotive industries [2][3]. To deplete the severity of this issue, a plethora of different ingredients such as liquid rubbers, core-shell particles (CSIMPs), and rigid organic and inorganic ingredients were used as impact modifiers particles (IMPs) of epoxy resin [4-7].

Generally speaking, soft IMPs (i.e. liquid rubbers and CSIMPs) could endanger significant improvement in the toughness of epoxy resin through various mechanisms such as deboning, cavitation, and crazing $[6,8]$. Nonetheless, incorporation of such IMPs in epoxy formulation could result in deterioration of other desired properties of the host polymer (such as modulus, stiffness, and tensile strength) [9]. On the other hand, rigid IMPs not only could enhance the toughness of epoxy resin by crack pinning, crack deflection and deflection/bifurcation effect of growing crack, but also could boost stiffness and modulus of the host polymer [10]. However, to reach a satisfying level of toughness, it is inevitable to use a relatively high dosage of such rigid IMPs in epoxy formulation. This obligation causes dramatic increase in viscosity and subsequently inroads serious difficulties in the processability of the obtained composite [11].

Regarding the mentioned limitations of IMPs and their inherent differences from the view point of toughening mechanisms, in the last decade, hybridization of different rigid and soft IMPs embedded into 
epoxy polymer matrix provided outstanding opportunities to the researchers for developing high performance nanocomposites with enhanced toughness and physico-mechanical properties [12][11][13] [14][15][16]. The obtained ternary nanocomposite could overcome the mentioned drawbacks and cause synergistic influences on the toughness and physico-mechanical properties of the obtained composite products.

It is no doubt that outstanding attributes of carbon nanotubes such as their high tensile strength and stiffness could remarkably enhance fracture toughness and physico-mechanical properties of conventional polymers [17]. Thus, among different rigid particles, it has been demonstrated that using carbon nanotubes as rigid fillers along with other soft IMPs could culminate a notable enhancement in fracture toughness of the obtained composites. Río et al. showed that the addition of a mixture of rigid carbon nanotube and soft polystyrene-polybutadiene-poly (methyl methacrylate) triblock copolymers led to the dramatic increase in both fracture toughness and fracture energy of the epoxy resin [18]. In another attempt it was revealed that using block copolymer could ameliorate the dispersion state of carbon nanotubes and causes a synergistic effect on the toughness of epoxy resin [19]. Jojibabu et al. showed that ternary composite of triblock copolymer, modified carbon nanotubes, and epoxy resin possess a remarkable improved toughness in comparison with binary composites [19].

The technique of experimental design due to its valuable assistance for comprehensive understanding of the process and interactive relationships between different variables, is known as a distinguished method in the engineering fields [20]. Among different methods, response surface method, which is a collection of mathematical and statistical techniques, has been used extensively to study and optimize the effect of diverse determining factors on the various parameters [21]. To the best of current authors' knowledge, there is no single published numerical and systematic study about the synergistic effects of MWCNTs and CSIMPs on the toughness and tensile properties of epoxy resin. Thus, a systematic study of the influence of multiwalled carbon nanotubes (MWCNTs) and CSIMPa on the mentioned attributes of epoxy resin is the main objective of this work. For this purpose, response surface methodology was used to find an applicable approximation function for predicting and optimization of the toughness and tensile properties of composites with various amounts of CSIMPs and MWCNTs.

\section{Experimental}

\subsection{Materials}

Monomers, glycidyl methacylate (GMA), methyl methacrylate (MMA), allyl methacrylate (ALMA) from Merck Chemical $\mathrm{Co}$. and butyl acrylate (BA) from Fluka were purchased and used as received. Emulsogen APS 100 from Clariant, ter-butyl perbenzoate (TBPB) from Merck Chemical Co., sodium formaldehyde sulfoxylate (SFS), ethylene diamine tertaacetic acid (EDTA), iron (II) sulfate heptahydrate $\left(\mathrm{FeSO}_{4} \cdot 7 \mathrm{H}_{2} \mathrm{O}\right)$, and ammonium persulphate (APS) from Alrdich, were used without any further purification.

MWCNTs with purity of $>95 \%$, length of 5-15 $\mu \mathrm{m}$, and outer diameter of 10-20 nm was purchased from Nutrino (Tehran, Iran). The epoxy resin was standard diglycidylether of bis-phenol A (DGEBA) 
(Epon828 from HEXION) with an epoxy equivalent molecular weight between $185 \mathrm{~g} / \mathrm{eq}$. and $192 \mathrm{~g} / \mathrm{eq}$. The curing agent was cycloaliphatic polyamine hardner (Epicure F205 from HEXION) with hydroxyl equivalent weight of 102-106 g/eq. Deionized water (DIW) was used in all recipes.

\subsection{Characterizations}

Size and external morphology of the prepared latex particles were investigated by scanning electron microscopy (SEM) with MIRA3 instrument from Tescan (The Czech Republic). Also, SEM images of the fracture surfaces of the epoxy specimens were used to assess the toughening mechanisms. The internal morphology of the prepared latex particles was studied by transmission electron microscopy (TEM) with CEM 902A ZEISS with an accelerating voltage of $80 \mathrm{keV}$ (Oberkochen, Germany). Tensile properties of the dog-bone-shaped specimens were obtained by a universal testing machine according to ASTM D-638. For each sample, the data reported are the average of five measurements. Fracture energy $\left(G_{I C}\right)$ and fracture toughness $\left(\mathrm{K}_{\mathrm{IC}}\right)$ were determined using a single-edge notch bend (SENB) specimen with dimensions of 6 $\times 12 \times 52.8 \mathrm{~mm}$. The tests were performed at a rate of $10 \mathrm{~mm} / \mathrm{min}$.

\subsection{Synthesis of the impact modifier particles}

Soft impact modifier particles with core-shell morphology was prepared through emulsion polymerization technique in two stages. At the first step, elastomeric cores of poly (BA-ALMA) were prepared through batchwise emulsion polymerization. For this purpose, $160 \mathrm{~g}$ DIW, $1 \mathrm{~g}$ Emulsogen APS 100, $30 \mathrm{~g} \mathrm{BA}$, and $0.16 \mathrm{~g}$ ALMA were premixed and charged into a $250 \mathrm{~mL}$, four-necked round bottom glass reactor equipped with reflux condenser, thermocouple, crescent Teflon-steel mechanical stirrer, and feeding inlets. The content of the reactor was deoxygenated by purging with nitrogen for $15 \mathrm{~min}$. The temperature was raised to $80^{\circ} \mathrm{C}$ and the polymerization reaction was started by the addition of solution of initiator $(0.04 \mathrm{~g}$ APS dissolved at $10 \mathrm{~mL}$ water). The conversion of the polymerization reaction was followed by gravimetric analysis of samples withdrawn from the reactor at regular time intervals. After $120 \mathrm{~min}$, the final conversion of the polymerization reaction was above $99 \%$.

In the second stage, copolymerization of MMA and GMA was occurred on the surface of the prepared elastomeric cores. For that, $200 \mathrm{~g}$ of the prepared latex, $9 \mathrm{~g}$ MMA, $1 \mathrm{~g}$ GMA, and $0.1 \mathrm{~g}$ TBPB charged into the reactor. The content of the reactor was mixed for $30 \mathrm{~min}$ at room temperature. Then, $10 \mathrm{ml}$ of the aqueous solution of $0.02 \mathrm{~g}$ EDTA, $0.01 \mathrm{~g} \mathrm{FeSO}_{4}$. $7 \mathrm{H}_{2} \mathrm{O}$, and $0.1 \mathrm{~g} \mathrm{SFS}$ was added into the reactor. The redox emulsion copolymerization was proceeded for $3 \mathrm{~h}$ at $30{ }^{\circ} \mathrm{C}$ to reach conversion of $>98 \%$. Then, the prepared latex was filtered through a $53 \mathrm{~mm}$ sieve and the filtrate was freezing for $12 \mathrm{~h}$ and freeze-drying for another $12 \mathrm{~h}$.

\subsection{Experimental design and fabrication of toughened specimens}

The CCD of RSM was used to assess the effects of the contents of MWCNTs and CSIMPs as independent factors on the fracture toughness and tensile properties of epoxy composites. Table 1 shows the ranges and levels of these factors. Total number of 13 experiments was designed by CCD algorithm which 
consists of 4 cube points, 4 axial points and 5 replications of the central points in cube to check the reproducibility variance.

Table 1. Real and coded levels of variables

\begin{tabular}{|c|c|c|c|c|c|c|}
\hline \multirow[t]{2}{*}{ Independent factor } & \multirow[t]{2}{*}{ Symbol } & \multicolumn{5}{|c|}{ Coded level } \\
\hline & & -1.5 & -1 & 0 & 1 & 1.5 \\
\hline MWNT (wt. \%) & $\mathrm{X}_{1}$ & 0 & 0.5 & 1.5 & 2.5 & 3 \\
\hline CSIMP (wt. \%) & $\mathrm{X}_{2}$ & 0 & 0.5 & 1.5 & 2.5 & 3 \\
\hline
\end{tabular}

Table 2 illustrates the details of the designed experimental conditions proposed by CCD. To find the best fitted model, the step-wise model fitting by Minitab 14 software was used. Equation 1, which is a secondorder empirical quadratic polynomial model, shows the behavior of the system

$$
Y=b_{0}+\sum_{i=1}^{k} b_{i} x_{i}+\sum_{i=1}^{k} b_{i i} x_{i}^{2}+\sum_{i}^{k} \sum_{j}^{k} b_{i j} x_{i} x_{j}
$$

Where $\mathrm{Y}$ is the predicted physico-mechanical response, bo is the constant, bi is the linear effect of the factor $x i(i=1,2$ and 3$)$, bii is the quadratic effect of the factor $x i$ and bij is the linear interaction effect between the input factors, $x i$ and $x j$.

To evaluate the effect of CSIMPs and MWCNTs on the physico-mechanical properties of epoxy resin, specimens with different contents of these reinforcing fillers were fabricated according to the Table 2 . For this purpose, definite amounts of MWCNTs and CSIMPs were added to $100 \mathrm{~g}$ of epoxy resin and stirred to form a uniform mixture. Then, to make sure that the fillers were uniformly distributed in the epoxy matrix, the mixture was processed by a three-roll milling (EXAKT 80E, Exakt Technologies, Germany) for 20 min via a three-roll grinder. The three-roll milling was used in gap mode with a $5 \mathrm{~mm}$ distance configuration between the center and apron roller. The speed of the apron roller was $260 \mathrm{rpm}$ and the roller speed ratio was 6:2:1. Then, $58 \mathrm{~g}$ Epicure F205 as a curing agent was added to the mixture and stirred with a glass rod. Finally, the prepared mixtures were degassed by a centrifugal deaerator for $10 \mathrm{~min}$ at $3000 \mathrm{rpm}$. The mixtures were poured into silicon molds and a two-step curing procedure was carried out; $2 \mathrm{~h}$ at $40^{\circ} \mathrm{C}$ then $4 \mathrm{~h}$ at $120^{\circ} \mathrm{C}$ using a ramp rate of $10^{\circ} \mathrm{C} / \mathrm{min}$.

\section{Results And Discussion}

\subsection{Preparation of impact modifier particles with core-shell morphology}

The capability of emulsion polymerization in preparing colloidal particles with disparate morphologies, physical, and chemical attributes makes it a unique and enticing polymerization method [22]. Here, 
thanks to these features, impact modifier particles with elastomeric core and epoxy-functionalized plastic shell was prepared successfully. A schematic illustration of the preparation steps of the CSIMPs is shown in Figure 1.

It is well known that using monomer such as ALMA, which has unsaturated bonds with different reactivity, could significantly enhance grafting efficiency, gel content, and structural stability of CSIMPs [23]. Linked to these rationales, in this work ALMA was chosen as a graflinking monomer in the formulation of the prepared elastomeric cores of CSIMPs. During the polymerization process, the colloidal stability of the growing latex particles was supplied by using a polymerizable anionic surfactant (Emulsogen APS 100). It well known that accumulations of surfactants in epoxy matrix could act as softening agents and render changes in the toughness and other physico-mechanical properties of epoxy polymers [24]. Here, it is suggested that through using a surfmer in emulsion polymerization formulation, the migration and accumulation of surfactants were hindered effectively.

To fabricate the plastic shell, redox emulsion copolymerization of MMA and GMA was occurred at the interfacial portion of elastomeric cores and aqueous medium. It was suggested that using a swelling time for dissolving monomers in poly (BA-ALMA) colloidal particles as well as proceeding the radical formation reactions at the interfacial region, could effectively minimize the probability of micellar and homogeneous nucleation [25]. In other words, it was surmised that exploiting a combination of oil soluble and water soluble ingredients as couple of redox initiator could guarantee that the copolymerization of MMA and GMA was mainly occurred at the surface region of elastomeric particles. Thus, by considering the water solubility of TBPB $(<1 \mathrm{~g} / \mathrm{L})$ and SFS $(\sim 600 \mathrm{~g} / \mathrm{L})$, the initiation step of the polymerization probably occurs at the surface of monomer-swollen poly particles. Also, iron (II) as co-catalyst and EDTA as a sequestering agent were used to increase the efficiency of the redox polymerization system and to prevent radical formation in an uncontrolled way, respectively [26].

Figure 2 shows the electron microscopy results of the prepared CSIMPs and manifest that employed synthesis method could successfully fabricate CSIMPs with average particle sized of $407 \mathrm{~nm}$.

\subsection{Modeling and Optimization using Response surface methodology}

The results in Table 2 were used to fit the polynomial models representing the Young's modulus (E), tensile strength $(S)$ and fracture toughness $\left(K_{I C}\right)$ of the toughened specimens (responses) as a function of the contents of MWCNTs $\left(w t . \% ; X_{1}\right)$ and CSIMPs $\left(w t . \% ; X_{2}\right)$. The following equations express the overall predictive model in terms of the coded variables:

$$
\begin{aligned}
& Y_{\text {Young's modulus }}=1882.9+664.2 X_{1}-345.7 X_{2}+164.6 X_{1}^{2}+160.3 X_{2}^{2}-580.5 X_{1} X_{2} \\
& Y_{\text {Tensile strength }}=34.364+5.633 X_{1}-1.423 X_{2}-2.132 X_{1}^{2}-2.059 X_{2}^{2}-7.935 X_{1} X_{2} \\
& Y_{\text {Fracture toughness }}=2.182+0.73826 X_{1}+1.16762 X_{2}-0.36754 X_{1}^{2}+0.09146 X_{2}^{2}-0.01181 X_{1} X_{2}
\end{aligned}
$$


Table 2. Experimental design matrix and responses

\begin{tabular}{|c|c|c|c|c|c|c|c|c|}
\hline \multirow[t]{2}{*}{ Run } & \multicolumn{2}{|c|}{ Factors } & \multicolumn{2}{|c|}{$\begin{array}{l}\text { Response: Young's } \\
\text { modulus, E (MPa) }\end{array}$} & \multicolumn{2}{|c|}{$\begin{array}{l}\text { Response: } \\
\text { Tensile } \\
\text { strength, S } \\
\text { (MPa) }\end{array}$} & \multicolumn{2}{|c|}{$\begin{array}{c}\text { Response: } \\
\text { fracture toughness, } \\
\mathrm{K}_{\mathrm{IC}}\left(\mathrm{MPa} . \mathrm{m}^{1 / 2}\right)\end{array}$} \\
\hline & $\begin{array}{c}\text { \% wt. } \\
\text { MWCNT }\end{array}$ & $\begin{array}{l}\text { \% wt. } \\
\text { CSIMP }\end{array}$ & Exp. & Fit & Exp. & Fit & Exp. & Fit \\
\hline 1 & 0.5 & 0.5 & 1480.680 & 1556.91 & 26.02 & 26.17 & 0.89 & 0.78 \\
\hline 2 & 1.5 & 1.5 & 1934.51 & 1882.85 & 34.45 & 34.36 & 2.27 & 2.18 \\
\hline 3 & 1.5 & 1.5 & 1863.62 & 1882.85 & 34.96 & 34.36 & 2.07 & 2.18 \\
\hline 4 & 0.5 & 2.5 & 1523.7 & 1612.02 & 31.46 & 31.32 & 2.24 & 2.35 \\
\hline 5 & 1.5 & 1.5 & 1892.91 & 1882.85 & 33.39 & 34.36 & 2.13 & 2.18 \\
\hline 6 & 2.5 & 0.5 & 2917.6 & 2958.44 & 40.35 & 40.73 & 1.83 & 1.78 \\
\hline 7 & 3 & 1.5 & 2745.4 & 2711.6 & 38.13 & 37.86 & 2.61 & 2.55 \\
\hline 8 & 1.5 & 0 & 2438.14 & 2388.79 & 34.02 & 33.73 & 0.98 & 1.11 \\
\hline 9 & 1.5 & 3 & 1762.94 & 1697.49 & 30.8 & 30.88 & 3.61 & 3.44 \\
\hline 10 & 2.5 & 2.5 & 1928.68 & 1981.59 & 31.7 & 31.8 & 3.16 & 3.32 \\
\hline 11 & 1.5 & 1.5 & 1927.73 & 1882.86 & 34.08 & 34.36 & 2.29 & 2.18 \\
\hline 12 & 0 & 1.5 & 1464.27 & 1383.27 & 26.55 & 26.6 & 1.07 & 1.08 \\
\hline 13 & 1.5 & 1.5 & 1824.21 & 1882.85 & 34.99 & 34.36 & 2.17 & 2.18 \\
\hline
\end{tabular}

The importance and statistical significance of the quadratic models was evaluated by the analysis of variance (ANOVA), which has been presented in Table 3. The ANOVA includes some statistic factors such as lack of fit, $R^{2}$, and adjusted $R^{2}$. The ANOVA results (Table 2 ) indicated that the models were highly significant, as $P$-value for the models was 0.000 . The high $\mathrm{R}^{2}$ values of the models demonstrated that they were capable of accurately predicting the mechanical properties of the prepared epoxy samples in the studied range. The insignificance "lack of fit" with P-value of higher than 0.05 indicated that in the models, LOF is meaningless and the models have appropriate accuracy for predicting of the results. All terms in the regression models are not equally important. The significance of each coefficient was determined by $P$ values (probability), which are listed in Table 3. The probability values less than 0.05 call for the rejection of the null hypothesis indicating that the particular term significantly affects the mechanical properties of the coatings. 
Table 3. Analysis of variance for the models and estimated regression coefficients

\begin{tabular}{|c|c|c|c|}
\hline \multirow{11}{*}{ 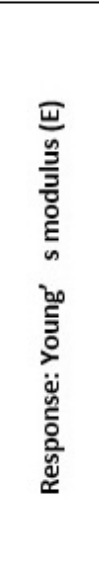 } & Term & Coef. & P-value \\
\hline & Constant & 1882.9 & 0.000 \\
\hline & $\%$ wt. MWCNT & 664.2 & 0.000 \\
\hline & $\%$ wt. CSIMP & -345.7 & 0.000 \\
\hline & $\%$ wt. MWCNT*\% wt. MWCNT & 164.6 & 0.029 \\
\hline & $\%$ wt. CSIMP*\% wt. CSIMP & 160.3 & 0.032 \\
\hline & $\%$ wt. MWCNT $\%$ wt. CSIMP & -580.5 & 0.000 \\
\hline & $\mathrm{R}-\mathrm{Sq}=98.4 \%$ & & \\
\hline & $R-S q(\operatorname{adj})=97.2 \%$ & & \\
\hline & P-value of Lack-of-Fit $=0.073$ & & \\
\hline & P-value of Regression $=0.000$ & & \\
\hline \multirow{8}{*}{ 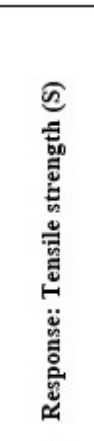 } & Term & Coef. & P-value \\
\hline & Constant & 34.364 & 0.000 \\
\hline & $\%$ wt. MWCNT & 5.633 & 0.000 \\
\hline & $\%$ wt. CSIMP & -1.423 & 0.002 \\
\hline & $\%$ wt. MWCNT*\% wt. MWCNT & -2.132 & 0.002 \\
\hline & $\%$ wt. CSIMP*\% wt. CSIMP & -2.059 & 0.002 \\
\hline & $\%$ wt. MWCNT*\% wt. CSIMP & -7.935 & 0.000 \\
\hline & $\mathrm{R}-\mathrm{Sq}=98.9 \%$ & & \\
\hline \multirow[t]{4}{*}{$\dddot{2}$} & $R-S q(\operatorname{adj})=98.1 \%$ & & \\
\hline & P-value of Lack-of-Fit $=0.846$ & & \\
\hline & P-value of Regression $=0.000$ & & \\
\hline & Term & Coef. & P-value \\
\hline \multirow{10}{*}{ 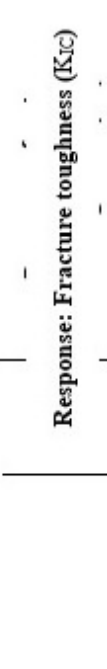 } & Constant & 2.18200 & 0.000 \\
\hline & $\%$ wt. MWCNT & 0.73826 & 0.000 \\
\hline & $\%$ wt. CSIMP & 1.16762 & 0.000 \\
\hline & $\%$ wt. MWCNT*\% wt. MWCNT & -0.36754 & 0.000 \\
\hline & $\%$ wt. CSIMP*\% wt. CSIMP & 0.09146 & 0.425 \\
\hline & $\%$ wt. MWCNT*\% wt. CSIMP & -0.01181 & 0.942 \\
\hline & $\mathrm{R}-\mathrm{Sq}=98.2 \%$ & & \\
\hline & $R-S q(\operatorname{adj})=97 \%$ & & \\
\hline & P-value of Lack-of-Fit $=0.113$ & & \\
\hline & P-value of Regression $=0.000$ & & \\
\hline
\end{tabular}

The obtained response surface and contour plots provide a procedure to predict the mechanical properties of the prepared epoxy specimens reinforced with various amounts of MWCNTs and CSIMPs. As it can be seen obviously in Figure 3-a, by increasing the content of MWCNTs, due to their intrinsic rigidity and significantly high Young's modulus, the $E$ values of the fabricated epoxy composites increased remarkably [27]. Also, it can be seen that addition of CSIMPs could not effectively alter the 
Young's modulus of the host polymer up to $2.2 \%$ wt. The plausible explanation for this observation could be due to the relatively low dosage of the used CSIMPs and also their ability for formation of covalent bonds with epoxy matrix [28]. The latter phenomena could effectively form spatial hindrance for polymer chains and increase the crosslink density of the final composite [29]. However, this effect could partially be compensated by the elastomeric core of the CSIMPs and result in the observed plateau region of modulus as a function of the content of CSIMPs. However, at higher levels of CSIMPs (>2.2\% wt.) an augmentation in modulus of the prepared composites was observed which could be attributed to the increasing in the content of the glassy functional shell of the CSIMPs in the composites structures [30]. As it can be seen clearly from the obtained contour plot, the measured modulus of the fabricated ternary composites could be explained by the cited rationales for individual effects of MWCNTs and CSIMPs.

It is well known that introducing MWCNTs in epoxy matrix could exert significant influence over tensile strength of the obtained composite [31]. This influence could be seen as a remarkable amelioration in tensile strength by increasing the content of MWCNTs in Figure 3-b. Also, it is seen that the addition of CSIMPs causes an improvement in tensile strength of the host polymer. This observation could be related to two pivotal traits of CSIMPs; i) the ability of the plastic shell for creation of covalent bonds with epoxy matrix, ii) crosslinked attribute of the core which could guarantee the structural stability of CSIMPs [32]. The obtained $S$ values of ternary composites revealed that the contributional effect of CSIMPs on the obtained results is more prominent than MWCNTs. In other words, at a constant concentration of MWCNTs, the addition of CSIMPs render a significant decreasing in tensile strength of the obtained nanocomposite, which could be attributed to the elastomeric portion of CSIMPs.

The influence of the contents of MWCNTs and CSIMPs on the fracture toughness of epoxy resin is shown in Figure 3-c. It can be seen clearly that both of the added ingredients could significantly increase the $\mathrm{K}_{\mathrm{IC}}$ of epoxy resin, however, as it is expected, the influence of CSIMPs is more prominent than MWCNTs. Moreover, it is observed that for the binary composites of MWCNTs/epoxy the measured fracture toughness is not directly proportional to the amounts of MWCNTs. This observation is probably due to the aggregation of MWCNTs which could be occurred at higher concentration of this material [33]. It is well-known that due to the enormous specific surface area of MWCNTs, they have strong tendency for creating clusters within polymer matrix. The formed clusters of MWCNTs could decrease the interfacial surface area between epoxy resin and rigid fillers, which consequently can reduce their interaction with growing crack and decrease the toughening performance of MWCNTs. An enticing additional insight is the synergistic toughening effects of MWCNTs and CSIMPs. It can be seen conspicuously that the ternary composite with $3 \%$ wt. MWCNTs and $3 \% w t$. CSIMPs possesses the highest value of facture toughness. This observation shows that the employed rigid and soft fillers could exert significant positive influence over fracture toughness of epoxy resin. It is substantiated that the dispersion state of MWCNTs could be improved significantly by the addition of block copolymers as IMPs, here it is suggested that the added CSIMPs could decrease the aggregated structures of MWCNTs and ameliorate their dispersion in epoxy matrix [18]. 
Optimization of effectual factors was mainly done to define the optimum formulation that caused the achievement of maximum $\mathrm{E}, \mathrm{S}$, and $\mathrm{K}_{\mathrm{IC}}$. The optimum values of selected factors were obtained by solving the regression equations (Equations 2-4). The optimum formulation for achieving to the cited aims were found to be as follow: MWCNTs (\% wt.) $=3$ and CSIMPs (\% wt.) $=1.03$. The maximum mechanical properties predicted by using the optimum values of factors were $\mathrm{E}=3014 \mathrm{MPa}$; $\mathrm{S}=40.57 \mathrm{MPa}$, and $\mathrm{K}_{\mathrm{IC}}=$ 2.2 $\mathrm{MPa} \cdot \mathrm{m}^{1 / 2}$. The tensile properties and toughness of the ternary composite in optimum condition obtained through the experiment were $\mathrm{E}=2970 \mathrm{MPa} ; \mathrm{S}=41.2 \mathrm{MPa}$, and $\mathrm{K}_{\mathrm{IC}}=2.1 \mathrm{MPa} \cdot \mathrm{m}^{1 / 2}$, which were in good consonance with the expected results. It can definitely be concluded that response surface methodology is a trustworthy tool for optimizing the mechanical properties of epoxy coatings.

\subsection{Fracture surface}

To assess the effect of MWCNTs and CSIMPs on the fracture toughness of the ternary composite, the fracture surface of epoxy polymer, binary and optimized ternary composites were comparatively examined by SEM. As it can be seen in Figure 4-a, the neat epoxy sample exhibits a typical fracture surface for unfilled epoxy resins, i.e. smooth fracture surface with the fine line patterns which indicates generally uninterrupted crack propagation and low fracture toughness [34]. On the other hand, for binary epoxy composite with $1.5 \%$ wt. MWCNTs (Figure 4-b), a rough fracture surface indicating a ductile fracture of the composite is observed. It has been reported that addition of MWCNTs to epoxy matrix could significantly increase the fracture toughness of host polymer through introducing restrictions to crack propagation and increasing the amount of plastic deformation [35]. In other words, the tip of the propagating crack tips could not break the strong MWCNTs and consequently they force to arrest or change their direction. Also, the high magnification SEM fractograph of this specimen (Figure 4-c) shows a plethora of pulled out nanotubes along with curved pattern which indicate a great deal of difficulty in crack initiation and propagation within the matrix of MWCNT containing samples in comparison with bared epoxy matrix [36]. Therefore, through the process of pulling out of MWCNTs from epoxy matrix, a great deal of dissipation of energy was occurred which cause a remarkable amelioration in fracture toughness of the prepared nanocomposites.

Figure 4-d shows the fractograph of binary composite of epoxy/CSIMPs. Rough fracture surface as well as spherical holes which are related to the deboning of CSIMPs and subsequent plastic deformation of matrix, indicate a ductile fracture of the prepared specimen [37]. It is surmised that stress-activated shear yielding in the high stress region around CSIMPs leads to the deformation of their rubbery portion and cavitation phenomenon, which in turn could significantly boost toughness of epoxy resin. In addition, as it can be seen obviously, the sizes of the holes are considerably bigger that the measured size of CSIMPs in SEM images (Figure 2). This observation is probably due to massive plastic deformation of the matrix around the AIMPs [38].

Fractographs of toughened samples with CNT and CSIMPs conspicuously show plastic deformation, crack deflection and pull out MWCNTs (Figure 4-e, f). This observation surmised that combination of 
crack deflection and inhibition of MWCNTs along with cavitation of CSIMPs could have synergistic toughening effects on epoxy matrix and enhance its toughness remarkably.

\section{Conclusion}

In this study, for the first time CCD/RSM design was adopted to determine the optimum condition for tensile properties and fracture toughness of epoxy/MWCNT/CSIMPs ternary composite. The CCD/RSM prepared the sufficient statistical data to fit a quadratic model in terms of the \%wt. MWCNTs and \%wt. CSIMPs in epoxy resin, on the tensile and toughness properties. The significance of the proposed models was indicated by the $p$-value of Regression $<0.0001$ and P-value of LOF $>0.05$. Analysis of variance showed good coefficient of determination values, $R^{2},(>98)$ for the studied properties. The optimum condition for maximum Young's modulus, tensile strength, and toughness of the epoxy composite obtained from RSM were $3 \%$ wt. MWCNTs and $1.03 \%$ wt. CSIMPs in epoxy of matrix. The sample prepared in optimal conditions indicated module $=3014 \mathrm{MPa}$, tensile strength $=40.57 \mathrm{MPa}$, and $\mathrm{K}_{\mathrm{IC}}=2.2$ MPa. $\mathrm{m}^{1 / 2}$. The obtained results indicated that the optimized ternary composites possess a good balance between Young's modulus, tensile strength, and toughness, which could not be achieved by other binary ones. The SEM images of the fractographes substantiated that combination of MWCNTs and CSIMPs could merge their toughening mechanisms and cause a synergistic toughening effect on the obtained ternary composite.

\section{Declarations}

\section{Author Contributions}

The authors contributed in the following ways: A.G., supervision, conceptualization, writing, review, and editing; M.S.S.D. experiments and analyses.

\section{Notes}

The authors declare no competing financial interest.

\section{References}

[1] Gupta, S. K., Shukla, D. K., Kaustubh Ravindra, D., Effect of nanoalumina in epoxy adhesive on lap shear strength and fracture toughness of aluminium joints. J Adhes. 97,117-139 (2021).

[2] Alfano, M. et al. Fracture toughness of structural adhesives for the automotive industry. Procedia. Struct. Integr. 5, 561-565 (2018).

[3] Hu, D. et al. Study on Toughness Improvement of a Rosin-Sourced Epoxy Matrix Composite for Green Aerospace Application. J. Compos. Sci. 4,168 (2020). 
[4] Bain, E. D. et al. Failure processes governing high-rate impact resistance of epoxy resins filled with core-shell rubber nanoparticles. J. Mater. Sci. 51, 2347-2370 (2016).

[5] Ha, S. R, Rhee, K. Y., Kim, H. C., Kim, J. T. Fracture performance of clay/epoxy nanocomposites with clay surface-modified using 3-aminopropyltriethoxysilane. Colloids Surfaces A Physicochem. Eng. Asp. 313. $112-115$ (2008).

[6] Johnsen, B. B., Kinloch, A. J., Mohammed, R. D., Taylor, A. C., Sprenger, S. Toughening mechanisms of nanoparticle-modified epoxy polymers, Polymer, 48, 530-41 (2007).

[7] Zhang, X., Xu, W., Xia, X., Zhang, Z., Yu, R. Toughening of cycloaliphatic epoxy resin by nanosize silicon dioxide. Mater. Lett. 60, 3319-3323 (2006).

[8] Chen, J., Kinloch, A.J., Sprenger, S., Taylor, A. C. The mechanical properties and toughening mechanisms of an epoxy polymer modified with polysiloxane-based core-shell particles. Polymer. 54, 4276-4289 (2013).

[9] Tsang, W. L., Taylor, A. C. Fracture and toughening mechanisms of silica-and core-shell rubbertoughened epoxy at ambient and low temperature. J. Mater. Sci. 54:13938-13958 (2019).

[10] Dittanet, P., Pearson, R. A. Effect of silica nanoparticle size on toughening mechanisms of filled epoxy. Polymer, 53,1890-1905 (2012).

[11] Bakar, M., Białkowska, A., Kuřitka, I., Hanuliková, B., Masař, M. Synergistic effects of thermoplastic and nanoclay on the performance properties and morphology of epoxy resin. Polym. Compos. 39, E2540-E2551 (2018).

[12] Wang, J. et al. Synergistically effects of copolymer and core-shell particles for toughening epoxy. Polymer 140, 39-46 (2018).

[13] Liang, Y. L., Pearson, R. A. The toughening mechanism in hybrid epoxy-silica-rubber nanocomposites (HESRNs). Polymer 51, 4880-4890 (2010).

[14] Li, T., He, S., Stein, A., Francis, L. F., Bates, F. S. Synergistic toughening of epoxy modified by graphene and block copolymer micelles. Macromolecules 49, 9507-9520 (2016).

[15] Ricciardi, M. R. et al. Mechanical properties of glass fibre composites based on nitrile rubber toughened modified epoxy resin. Compos. Part. B. Eng. 139:259-267 (2018).

[16] Hsieh, T. H. et al.The toughness of epoxy polymers and fibre composites modified with rubber microparticles and silica nanoparticles. J. Mater. Sci. 45, 1193-1210 (2010).

[17] Imtiaz, S. et al. A review featuring fabrication, properties and applications of carbon nanotubes (CNTs) reinforced polymer and epoxy nanocomposites. Chinese J. Polym. Sci. 36:445-461 (2018). 
[18] Gómez-del, Río. T., Salazar, A., Pearson, R. A., Rodríguez, J. Fracture behaviour of epoxy nanocomposites modified with triblock copolymers and carbon nanotubes. Compos. Part. B Eng. 87:343-349 (2016).

[19] Schuster, M. B., Opelt, C. V., Becker, D., Coelho, L. A. F. Role and sinergy of block copolymer and carbon nanoparticles on toughness in epoxy matrix. Polym. Compos. 39, E2262-E2273 (2018).

[20] Song, H., Chung, H., Nam, K. Response surface modeling with Box-Behnken design for strontium removal from soil by calcium-based solution. Environ. Pollut. 274, 116577 (2021).

[21] Dorraji, M. S. S., Rasoulifard, M. H., Khodabandeloo, M. H., Rastgouy-Houjaghan, M., Zarajabad, H. K. Microwave absorption properties of polyaniline- $\mathrm{Fe}_{3} \mathrm{O}_{4} / \mathrm{ZnO}$-polyester nanocomposite: preparation and optimization. Appl. Surf. Sci. 366, 210-218 (2016).

[22] Gharieh, A., Khoee. S., Mahdavian, A. R. Emulsion and miniemulsion techniques in preparation of polymer nanoparticles with versatile characteristics. Adv. Colloid. Interface Sci. 269,152-186 (2019).

[23] Bouvier-Fontes, L., Pirri, R., Asua, J. M.. Leiza, J. R. Cross-linking emulsion copolymerization of butyl acrylate with diallyl maleate. J. Polym. Sci. Part A Polym. Chem. 43, 4684-4694 (2005).

[24] Jensen, R. E.et al. Characterization of epoxy-surfactant interactions. J. Polym. Sci. Part B Polym. Phys. 36, 2781-2792 (1998).

[25] Gharieh, A., Mahdavian, A. R., Salehi-Mobarakeh, H. Preparation of core-shell impact modifier particles for PVC with nanometric shell thickness through seeded emulsion polymerization. Iran. Polym. J. 23, 27-35 (2014).

[26] van Herk. A. M. Chemistry and technology of emulsion polymerisation 58-59 (John Wiley \& Sons; 2013).

[27] Gojny, F. H., Wichmann., M. H. G., Köpke, U., Fiedler, B., Schulte, K. Carbon nanotube-reinforced epoxy-composites: enhanced stiffness and fracture toughness at low nanotube content. Compos. Sci. Technol. 64, 2363-2371 (2004).

[28] Giannakopoulos, G., Masania, K., Taylor, A. C. Toughening of epoxy using core-shell particles. J. Mater. Sci. 46, 327-338 (2011).

[29] Mirmohseni, A., Gharieh, A., Khorasani, M. Silica encapsulation by miniemulsion polymerization: $A$ novel approach of efficient chemical functionalization on silica nanoparticles. Polymer 98, 182-189 (2016).

[30] Ren, X. et al. Critical rubber layer thickness of core-shell particles with a rigid core and a soft shell for toughening of epoxy resins without loss of elastic modulus and strength. Compos. Sci. Technol. 153, 253-260 (2017). 
[31] Pothnis, J. R., Kalyanasundaram, D., Gururaja, S. Enhancement of open hole tensile strength via alignment of carbon nanotubes infused in glass fiber-epoxy-CNT multi-scale composites. Compos. Part $A$ Appl. Sci. Manuf. 140, 106155 (2021)

[32] Bajpai, A., Wetzel, B., Klingler, A., Friedrich, K. Mechanical properties and fracture behavior of highperformance epoxy nanocomposites modified with block polymer and core-shell rubber particles. J. Appl. Polym, Sci. 137, 48471 (2020).

[33] Esmaeili, A., Sbarufatti, C., Jiménez-Suárez, A., Ureña, A., Hamouda, A. M. S. A comparative study of the incorporation effect of SWCNT-OH and DWCNT with varied microstructural defects on tensile and impact strengths of epoxy based nanocomposite. J. Polym. Res. 27, 1-10 (2020).

[34] Quan, D., Ivankovic, A. Effect of core-shell rubber (CSR) nano-particles on mechanical properties and fracture toughness of an epoxy polymer. Polymer 66, 16-28 (2015).

[35] Rafiee, M., Nitzsche, F., Labrosse, M. R. Effect of functionalization of carbon nanotubes on vibration and damping characteristics of epoxy nanocomposites. Polym. Test 69, 385-95 (2018).

[36] Tang, L. C. et al. Fracture toughness and electrical conductivity of epoxy composites filled with carbon nanotubes and spherical particles. Compos. Part A Appl. Sci. Manuf. 45, 95-101 (2013).

[37] Xu, C. et al. Enhanced toughness and thermal conductivity for epoxy resin with a core-shell structured polyacrylic modifier and modified boron nitride. RSC Adv. 9, 8654-8663 (2019).

[38] Jaafar, C. N. A., Zainol, I., Ishak, N. S., llyas, R. A., Sapuan, S. M. Effects of the liquid natural rubber (LNR) on mechanical properties and microstructure of epoxy/silica/kenaf hybrid composite for potential automotive applications. J. Mater. Res. Technol.12, 1026-1038 (2021).

\section{Figures}




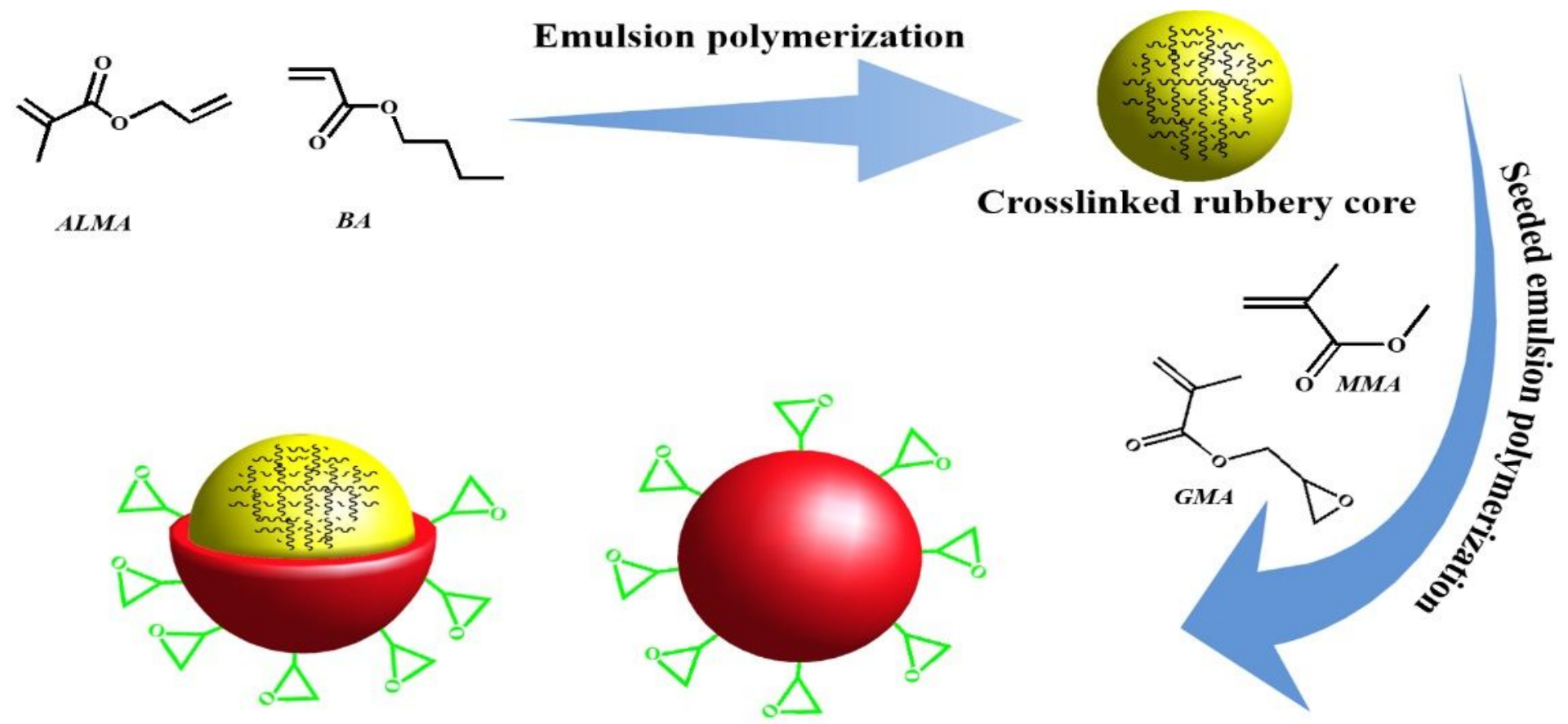

Epoxy functionalized core-shell nanoparticle and its cross-section draw

Figure 1

Schematic illustration of preparation steps of CSIMPs 

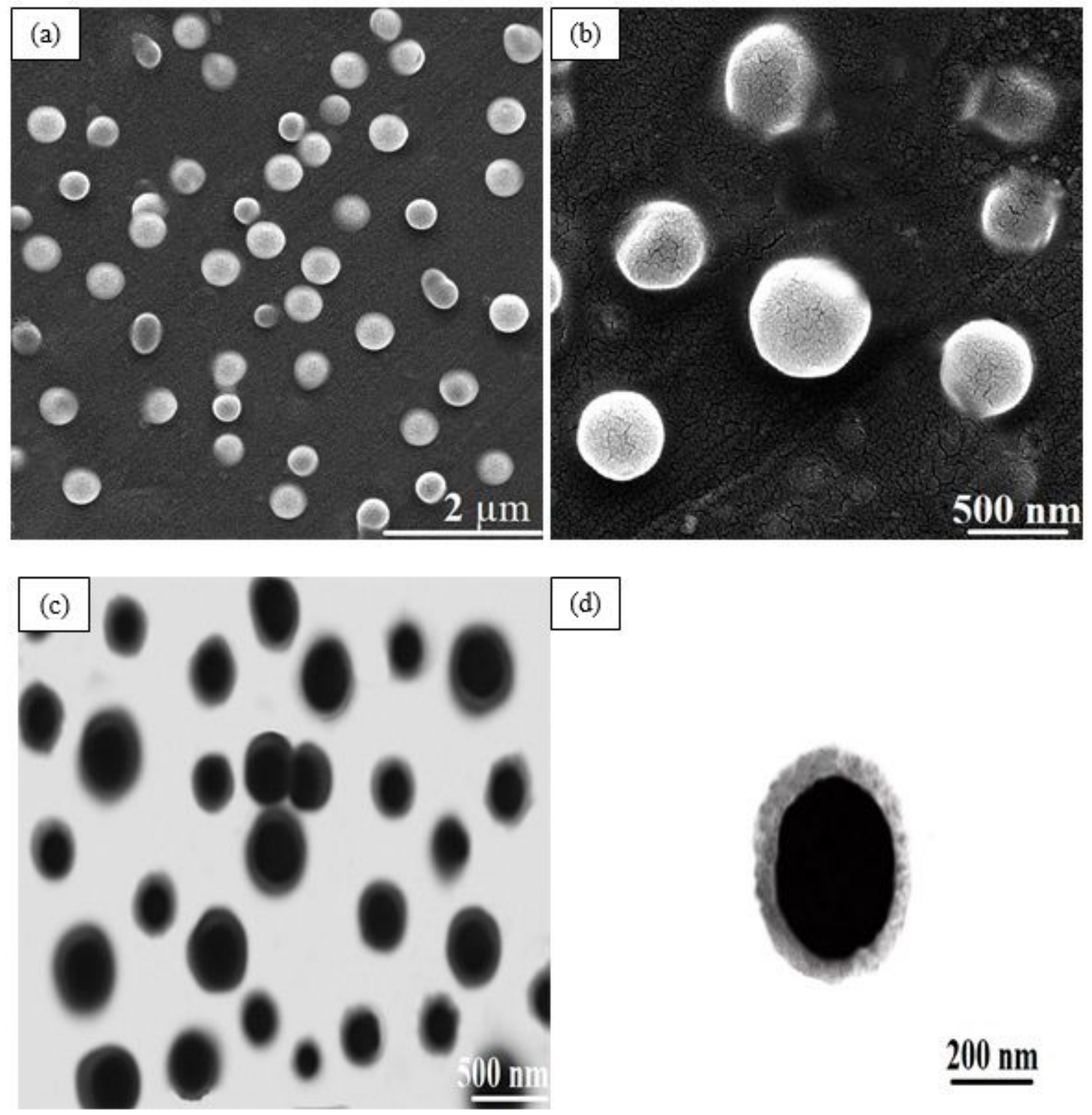

(d)

Figure 2

SEM $(a, b)$ and TEM $(c, d)$ images of the prepared IMPs 
(a)
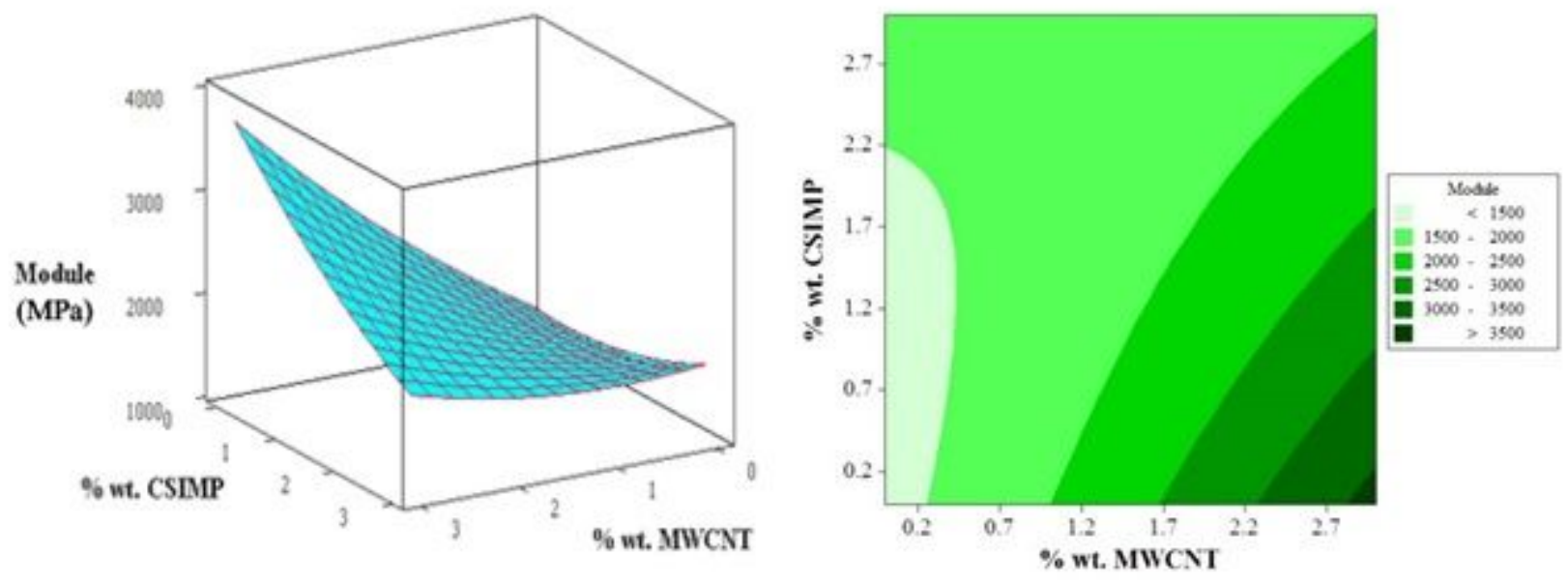

(b)
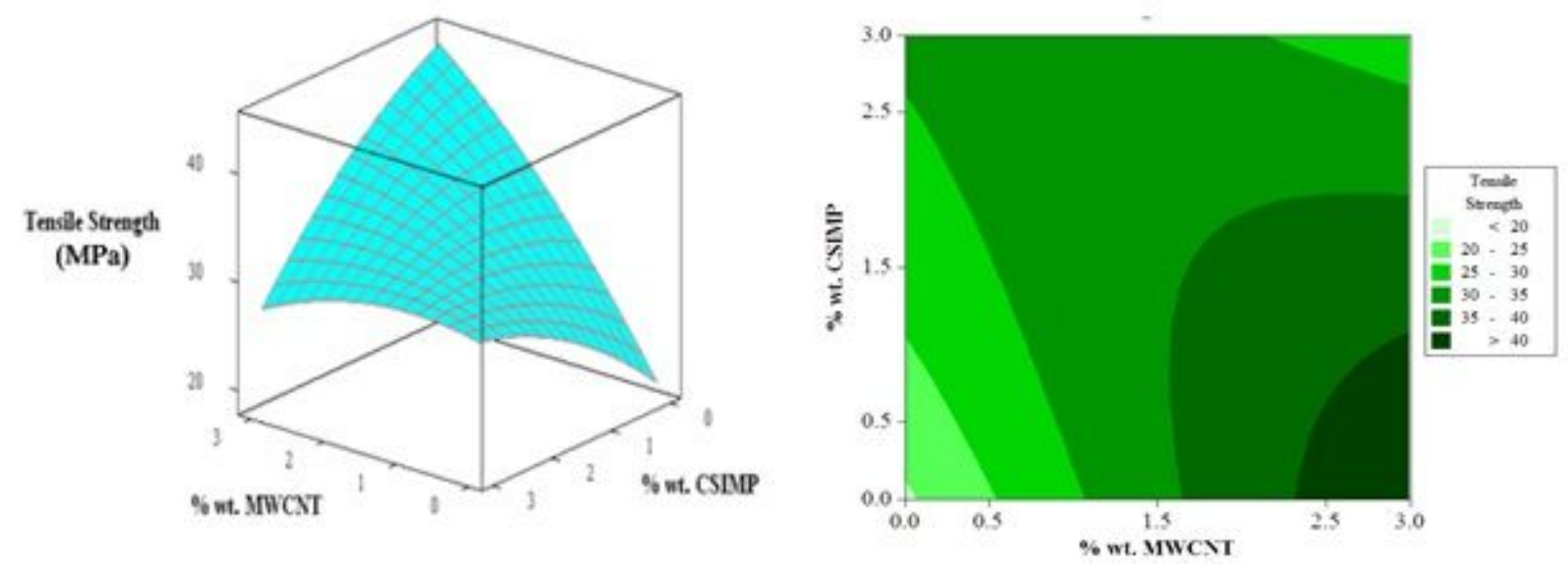

(c)
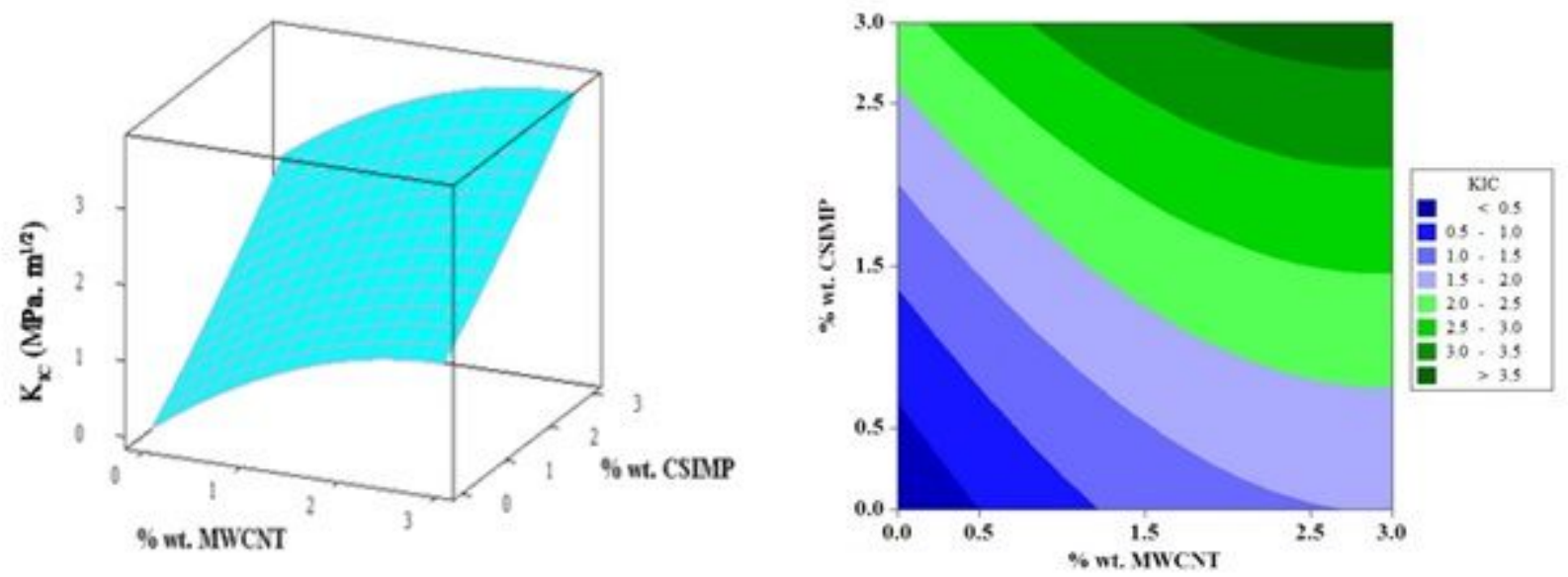

Figure 3

Response surface and Contour plots of tensile properties and toughness of epoxy composites 

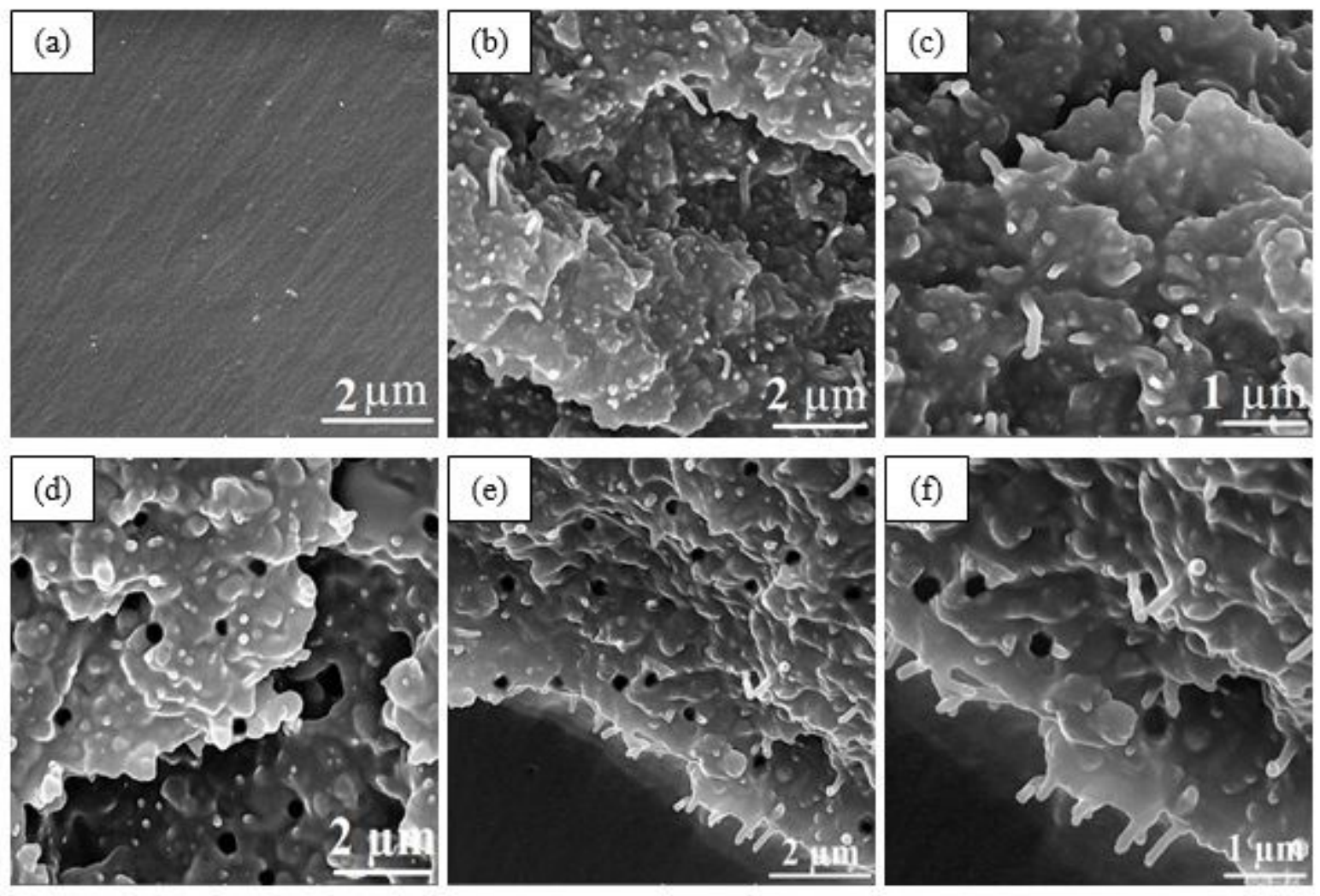

\section{Figure 4}

Fractographs of (a) neat epoxy, (b, c) epoxy composite with 1 \%wt. MWCNTs, (d) epoxy composite with $03 \% \operatorname{CSIMP},(\mathrm{e}, \mathrm{f})$ composite with $0.5 \%$ MWCNT and $1.5 \%$ CSIMP 